\title{
Relationships between District Size, Socioeconomics, Expenditures, and Student Achievement in Washington
}

\author{
Vince Diaz \\ Seattle Pacific University
}

The purpose of this article is to describe the relationship between district size, socioeconomic status, actual levy percentages, and their predictive influence on the 2003 Washington Assessment of Student Learning results for $4^{\text {th }}$ and $7^{\text {th }}$ grade students in Reading and Mathematics. The convenient sample was 82 Washington State $2^{\text {nd }}$-Class school districts with enrollments between 500-2,000 students. The results indicated: (a) no significant correlations between achievement and district size; (b) socioeconomic status was the best predictor of achievement; and (c) actual levy percentages and student outcomes were significantly correlated in the positive direction.

\section{Introduction}

The purpose of this state study was to: (a) to explore relationships between district size and student achievement; and (b) to explore relationships between socioeconomic status and student achievement; and (c) to explore relationships between district financial resources allocation as measured by actual levy percentages and student achievement in Washington State $2^{\text {nd }}$ class school districts. The study also examined which of these variables (district size, SES, and actual levy percentages) was the best predictor of student achievement.

Washington school districts with enrollment parameters below 2,000 are classified as second-class school districts (Revised Code of Washington 28A.300.065). Districts below the enrollment levels of 500 were not included in the study, since statistical procedures are difficult to conduct with low sample and population targets. Consequently, eighty-two Washington school districts met the enrollment parameters between 500 to 2,000 students for this study.

The sample of districts represented approximately 28\% of the total number of 296 school districts in Washington State. According to the Human Services policy Center at the University of Washington, 70\% of these 82 school districts were classified rural, 29\% suburban, and the remaining 1\% in the urban category (Washington Kids Count, 2003). Further analysis revealed that the 82 school districts were located in 34 out of 39 Washington State counties. Western Washington counties were represented by forty districts and likewise, Eastern Washington counties were represented by the other 42 school districts. Generally, the eastern demarcation for Washington State is considered east of the Cascades mountain range.

District size was investigated as a factor due to current literature regarding the efficacy of system size and its influential dynamics on student outcomes. Socioeconomic status was defined as free and reduced meal percentages at the district level. Finally, actual levy percentages represented a component of district financial resources. In
Washington State, actual levy percentages represent local property taxes in which a local district includes in their overall budget for the purpose of general fund revenues. For the purpose of this study, it was hypothesized that student achievement was significantly influenced by socioeconomic status but that smaller districts mitigated the negative influence of SES. Secondly, it was hypothesized that actual levy percentages as an indicator of a district's financial resources would have a significant correlation with student outcomes.

Despite the extensive and diverse solutions to overhaul our schools following the unveiling of A Nation at Risk in 1983, and the earlier publication by Conant (1959), a contemporary resurgence of empirical interest has shifted towards school system size, socioeconomic status of students, district financial resources allocation, and their influence on student outcomes. In a major study that involved a sampling of 38 states, Walberg and Walberg (1994) reported that achievement is significantly and inversely related to average district and school sizes, and state share of expenditures. They further concluded states with larger districts and larger schools and that pay a greater share of public school costs do worse in achievement.

Howley (1989) examined the efficiency of 178 Kentucky school districts by level of expenditures per student on three socioeconomic variables (assessed valuation, personal income, and percent of students receiving free or reduced lunch) in order to assess the maximum influence of SES on expenditures. Howley reported a statistically significant relationship was determined to exist between efficiency and (a) smallness and (b) district type. He further observed certain small and independent districts spend more than can normally be expected of them to educate their students. In other words, these inefficient districts spent more to educate their students but also received better results on Kentucky's criterion-referenced exams at the second, third, and ninth grade levels. 
Prior investigations in the late 1980's also found a negative relationship between district or school size and student performance (Fetler, 1989; Friedkin \& Necochea, 1988). Howley (1989) reviewed the Friedkin and Necochea study and concluded large schools and districts magnify the achievement differences of students in impoverished as compared to affluent communities. Howley hypothesized that such academic variances accumulate and diverge ever more sharply over time for students who continue to be educated in large schools and districts.

Huang and Howley (1993) examined the interactive hypothesis that school size mediates the effect of disadvantaged status on the achievement of individual students. In their attempt to relate their findings to the Friedkin and Neccochea (1988) study, Huang and Howley's study observed similar results of an interaction between socioeconomic status and school size in Alaska. Essentially, disadvantaged students performed better in smaller schools in Alaska and worse in larger schools and districts.

In a later study, Howley (1996) attempted to replicate the Friedkin and Neccochea (1988) California study that reported substantial school and district size effects on achievement. Utilizing a 1990 Virginia data set, Howley's study provided evidence that school or district size interacted with socioeconomic status to influence student achievement in West Virginia. Howley concluded smaller schools and districts seem to hold particular benefits for educating relatively impoverished students. But larger schools and districts seem to hold particular benefits for educating relatively affluent students.

In a similar vein, Bickel and Howley (2000) investigated the joint influence of school and district size on school performance among Georgia schools using the performance of the eighth and eleventh grades. Bickel and Howley's findings reported small size is good for the performance of impoverished schools; as well as small district size is also good for the performance of schools in Georgia. They further concluded that additional replications to investigate the size issue within impoverished communities holds much merit. Additionally, Howley, Strange, and Bickel (2000) and Howley (2003) reviewed widespread research interest in school system size and suggested academic benefits can exist in schools that are less than 1,000 for communities that serve both impoverished and affluent student clientele.

Recent national investigations continue to yield results which substantiate the influence of school/district size, funding equity, and socioeconomic status of students on student achievement (Lewis, 2008; Mason, 2007; Sirin, 2005; Spears, 2007; Weber, 2005). Weber's regression results indicated that size was negatively associated with achievement among $6^{\text {th }}$ through $10^{\text {th }}$ grade for all students, economically disadvantaged students, and English learners. Further, analysis of variance under Weber's investigation revealed advantaged and disadvantaged students' achievement increased in smaller school settings. Sirin's meta-analysis reviewed the literature on socioeconomic status (SES) and academic achievement in journal articles published between 1990 and 2000. Although the results indicated a medium to strong SES-achievement relationship, the strength of the relationship is also contingent upon school level, minority status, and the school's location.

In addition to the prolific empirical contributions by Howley and recent investigations by other researchers, there have been numerous investigations in Washington State on student outcomes influenced by socioeconomic status, school system size, ethnic composition, district financial resources, and parental income levels (Fouts, 1999; 2002; 2003; Fouts, Abbott, \& Baker, 2002; Fouts, Brown, \& Thieman, 2002; Fouts, Stuen, Anderson, \& Parnell, 2000; Lake, Hill, O’Toole, \& Celio, 1999; Lake, McCarthy, Taggart, \& Celio, 2000; McCarthy, 2001; Mork, 1998; Newbill, 1999; Peterson \& Abbott, 2005; Portin, Plecki, Elfers, \& Beck, 2003; Van Slyke, 1998). Four key investigations in Washington State which supported the overall intent of this study are reviewed here

Abbott and Joireman (2001) explored the influence on student achievement by ethnic composition and income levels of students' families. Their findings indicated low income explains a much larger percentage of variance in academic achievement than ethnicity across six groups of Washington state students. Abbott and Joireman's investigation reiterates the relative powerful influence of poverty on the overall scholastic achievement level of students. Their study concluded that low income is the stronger predictor of school achievement, and nonwhite families are over-represented among the lower incomes.

Abbott, Joireman, and Stroh (2002) examined the efforts of Washington elementary schools whose students were meeting the standards on the Washington Assessment of Student Learning (WASL). Replicating Bickel and Howley (2000) methodology, these investigators examined three variables (district size, school size, and socioeconomic status) which influenced the performance levels for $4^{\text {th }}$ and $7^{\text {th }}$ grade students on the WASL, and mitigated the single best predictor of student achievement, free and reduced meals, an indicator of poverty levels. They concluded large district size is detrimental to achievement in Washington $4^{\text {th }}$ and $7^{\text {th }}$ grades in that it strengthens the negative relationship between poverty and student achievement. Further,they observed district affluence did not have a significant impact over the school size-student achievement relationship, butdid note the tendency for larger schools to be somewhat more beneficial in more affluent districts and equivalently, and for smaller schools to be more beneficial in less affluent districts.

Boyle (2002) discussed the unique financial hurdles that small Washington school districts face in light of the call for higher standards and recent federal legislation (NCLB) and identified the following crucial financial issues relative to small, rural schools: 
1. Per-pupil allocations of state funds do not consider the economy of scale that benefits larger school systems.

2. Budgets and student outcome indicators are sensitive to the demographic dynamics for a small district from year to year.

3. Special student populations place dramatic impact on small district resources.

4. Transportation costs in rural areas can tax the budget structures of a small district.

5. Assessed tax valuations vary from district to district. Therefore, patrons in property-poor districts may pay higher tax rates compared to other patrons who inhabit highly assessed properties.

6. For districts that do not have a high school, they must pay non-high payments to another servicing district along with higher transportation costs (Boyle, 2002, p. 5).

Eigenbrood (2004) replicated Abbott, Joireman, and Stroh's (2002) study and the results indicated a failure to find a significant interaction between school size and district poverty for the Washington Assessment of Student Learning (WASL) scores. In contrast, the results in Eigenbrood's study replicated the major study by Bickel and Howley (2000), which indicated a significant interaction between school size and district poverty when Iowa Test of Basic Skills (ITBS) scores were used in the analysis. Although, the Eigenbrood's results replicated the Bickel and Howley investigation and not the results of the earlier Washington study by Abbott, Joireman, and Stroh (2002), the results do suggest that the relationship between system size and socioeconomic status is a very complicated issue.

\section{Participants}

A target population of second-class Washington school districts with a 2003 enrollment between 500-2,000 students was the primary unit of analysis. Washington school districts with enrollment below 2,000 are classified as second-class school districts. Eighty-two Washington school districts met these particular enrollment parameters. The sample of districts was located in 34 out of the 39 total Washington State counties, with 40 of the districts residing in western Washington and the remaining 42 in the eastern portion of the state. Each school district represented in the target population was informed of the purpose of the study via a mailing to each district superintendent. Approximately $65 \%$ of the districts acknowledged an interest as a participating district with a return response form. The positive response rate indicated a high interest in the study by the districts.
The target population was further grouped by three tiers of sampling. The first tier were districts with an enrollment level between 500-999 students $(n=43)$. The second tier included enrollment parameters between 1,000 through 1,499 students $(n=25)$; and the final tier were districts with an enrollment between 1,500 through 2,000 students $(n=14)$. Statistical comparisons were conducted based on these tiered enrollment levels as well as tiered district socioeconomic levels, and tiered actual levy percentage levels.

\section{Methodology}

A correlational design was utilized in the exploration of the relationships among the variables district size, socioeconomic status, actual levy percentages, and the 2003- $4^{\text {th }}$ and $7^{\text {th }}$ grade Washington Assessment of Student Learning (WASL) results in mathematics and reading. In conjunction, multiple regression procedures with simultaneous entry of the predictors were applied to ascertain the most influential predictors of student outcomes. Regression analysis indicated the amount of variation among the WASL scores that were ascertained by the relationship between the reading and math scores and the interactive combination of district size, socioeconomic status, and actual levy percentages.

Four research questions were investigated to explore the relationship among district size, socioeconomic status, actual levy percentages, and student achievement on the WASL:

1. What is the relationship between student achievement and district enrollment size?

2. What is the relationship between achievement and the socioeconomic status of students in the districts?

3. What is the relationship between academic achievement and districts financial resource allocation (as measured by actual levy percentages)?

4. Which of these variables is the most influential predictor of student achievement in second-class Washington State school districts: district size, SES, or actual levy percentages?

\section{Results}

The mean performance of $4^{\text {th }}$ and $7^{\text {th }}$ grade students in sample districts compared favorably with statewide means of first class school districts on the 2003 Washington Assessment of Student Learning for reading at the $4^{\text {th }}$ grade level. However, the mean standard scores in the sample districts were less than the means of first class school districts for the $4^{\text {th }}$ and $7^{\text {th }}$ grade mathematics, and $7^{\text {th }}$ grade reading. The standard score differences ranged from 1.0 to 
7.6. The most pronounced difference was represented in the standard score results for the $7^{\text {th }}$ grade mathematics between the sample study and Washington first class school districts.
Table 1 presents the results between the second-class school districts in this study and all of the Washington first-class school districts (> 2,000 students).

Table 1

2003 WASL Results: Sample $\left(2^{\text {nd }}\right.$ Class $)$ and Statewide $\left(1^{\text {st }}\right.$ Class $)$

\begin{tabular}{llll}
\hline & \multicolumn{1}{c}{ Standard Score } & Mean Results & \\
\hline WASL Subtest & Sample $M$ & Statewide $M$ & Difference \\
\hline Reading $4^{\text {th }}$ & 402.9 & 401.9 & 1.0 \\
Reading $^{\text {th }}$ & 393.8 & 396.5 & 2.7 \\
Mathematics $4^{\text {th }}$ & 394.8 & 400.6 & 5.8 \\
Mathematics $7^{\text {th }}$ & 374.5 & 382.1 & 7.6 \\
\hline
\end{tabular}

Enrollment tiers and 2003 Mean Results for Academic Achievement

The mean standard score results for $4^{\text {th }}$ grade reading (403) was similar across the enrollment tiers. Minor standard score differences were indicated on $7^{\text {th }}$ grade reading, and $4^{\text {th }}$ and $7^{\text {th }}$ grade mathematics. Table 2 summarizes the mean results for each WASL subtest on the four tiers of enrollment from the sample districts.

Table 2

Enrollment Tiers and 2003 Academic Achievement

\begin{tabular}{lcccccccc}
\hline & \multicolumn{2}{c}{$500-999$} & $1,000-1,499$ & $1,500-2,000$ & $500-2,000$ \\
\hline Subtest & $M$ & $S D$ & $M$ & $S D$ & $M$ & $S D$ & $M$ & $S D$ \\
\hline Reading 4 & 403 & 6.4 & 403 & 7.6 & 403 & 8.5 & 403 & 7.1 \\
Reading 7 & 393 & 6.6 & 393 & 6.4 & 396 & 7.4 & 394 & 6.6 \\
Math 4 & 396 & 11.7 & 392 & 12.5 & 396 & 15.4 & 395 & 12.6 \\
Math 7 & 373 & 18.6 & 375 & 18.8 & 380 & 21.2 & 374 & 19.0 \\
\hline
\end{tabular}




\section{Student eligibility for Free and Reduced Meals and 2003 WASL Achievement Results}

The 2003 WASL results in reading and mathematics for $4^{\text {th }}$ and $7^{\text {th }}$ graders in the study sample indicated an increase in standard scores as the free and reduced meal rates decreased. Table 3 summarizes data on free and reduced meals tiers and achievement on the WASL for 2003. Three tiers were selected for comparison: 1) 4-30\%; 2) 31-59\%; and 3) $60-91 \%$.

Table 3

Free and Reduced Meal Percentages and 2003 WASL Achievement

\begin{tabular}{|c|c|c|c|c|c|c|}
\hline \multicolumn{3}{|c|}{$4-30 \%$} & \multicolumn{2}{|c|}{$31-59 \%$} & \multicolumn{2}{|c|}{$60-91 \%$} \\
\hline Subtest & $S D$ & $M$ & $S D$ & $M$ & $S D$ & $M$ \\
\hline Reading 4 & 408.2 & 3.8 & 404.3 & 4.0 & 394.1 & 7.4 \\
\hline Reading 7 & 400.0 & 5.9 & 394.5 & 3.7 & 386.9 & 4.5 \\
\hline Mathematics 4 & 403.4 & 8.4 & 396.4 & 9.1 & 382.7 & 12.9 \\
\hline Mathematics 7 & 390.4 & 14.7 & 380.6 & 15.7 & 354.3 & 14.7 \\
\hline
\end{tabular}

\section{Discussion of Findings}

What is the relationship between student achievement and district enrollment size?

Correlation coefficients were computed by enrollment tiers for the sample districts and the 2003 WASL $4^{\text {th }}$ and $7^{\text {th }}$ grade mean standard scores for reading and mathematics. Using the Bonferroni approach to control for Type I error across the 5 correlations, a $p$ value of less than $.01(.05 / 5=$ $.01)$ was required for significance. No statistically significant correlations at the .01 alpha levels were evident (2-tailed).

What is the relationship between student achievement and the socioeconomic status of students in the districts?

Correlation coefficients were computed between the free and reduced meal percentages of the sample districts and the 2003 WASL $4^{\text {th }}$ and $7^{\text {th }}$ mean standard scores for the reading and mathematics subtests. The Bonferroni method was again applied to control for Type I error across the number of correlations, hence an adoption of an alpha level of .01. The results were statistically significant in the negative direction.

What is the relationship between student achievement and Washington State districts financial resource allocation (as measured by actual levy percentages)?
Correlational coefficients were computed among the 2003 actual levy percentages of the sample districts and the WASL subtests. Again, due to the large number of correlations and to control for the probability of a Type I error, the Bonferroni method was applied. All of the correlations across the (0-28\%) actual levy percentage tiers and the WASL subtests were statistically significant in the positive direction.

Which of these variables is the most influential predictor of student achievement in small Washington state school districts: district size, socioeconomic status of students, and or actual levy percentages?

Reading $4^{\text {th }}$ Grade. Multiple regression results revealed that the socioeconomic status of the district was the most influential predictor of $4^{\text {th }}$ grade reading at the .01 level of significance. The relationship between SES and $4^{\text {th }}$ grade reading achievement was very strong. The proportion of variance indicated $55 \%$ of the variance in $4^{\text {th }}$ grade reading was predictable from SES. The entrance of district size and actual levy percentages as combined predictors with SES added a minuscule increment to the coefficient of determination $\left(R^{2}\right)$ in the 3-predictor model, raising $\left(R^{2}\right)$ to $57 \%$. Table 4 presents the results for $4^{\text {th }}$ grade reading. 
Table 4

Most Influential Predictor of 2003 WASL $4^{\text {th }}$ Reading: Socioeconomic status (SES), District size, and Actual levy percentages

$4^{\text {th }}$ Grade Reading

\begin{tabular}{lccccccc}
\hline $\begin{array}{l}\text { Predictor } \\
\text { SES }\end{array}$ & $B$ & Beta & $r$ & $R$ & $R^{2}$ & $\begin{array}{c}R^{2} \\
\text { Increment }\end{array}$ \\
\hline Square & .547 \\
District Size & -28.608 & -.793 & $-.744^{* *}$ & .744 & .553 & .556 \\
Actual Levy Percents & -.002 & -.120 & -.020 & .753 & .567 & .014 & .003 \\
\hline
\end{tabular}

$F(3,78)=34.45 . * *<.01$

Reading $7^{\text {th }}$ Grade. The proportion of variance indicated $62 \%$ of the variance in $7^{\text {th }}$ grade reading was predictable from SES. The addition of district size and actual levy percentages as combined predictors with SES added a non-significant increment to the coefficient of determination in the 3-predictor model. Table 5 presents the results for $7^{\text {th }}$ grade reading.

Table 5

Most Influential Predictor of 2003 WASL $7^{\text {th }}$ Reading: Socioeconomic status (SES), District size, and Actual levy percentages

$7^{\text {th }}$ Grade Reading

\begin{tabular}{lcccccc}
\hline $\begin{array}{l}\text { Predictor } \\
\text { SES }\end{array}$ & B & Beta & $r$ & $R$ & $R^{2}$ & $\begin{array}{c}R^{2} \\
\text { Increment }\end{array}$ \\
\hline District Size & -27.770 & -.821 & $-.790^{* *}$ & .790 & .624 & .619 \\
Actual Levy Percents & .000 & .023 & .127 & .790 & .625 & .001 \\
\hline
\end{tabular}

$F(3,78)=43.77 . * * p<.01$

Mathematics $4^{\text {th }}$ Grade. Multiple regression results revealed that the socioeconomic status of the district was the most influential predictor of $4^{\text {th }}$ grade mathematics at the .01 level of significance. The relationship between SES and $4^{\text {th }}$ grade mathematics achievement was also strong. Regression analysis indicated $47 \%$ of the variance in $4^{\text {th }}$ grade mathematics was predictable from SES. The introduction of district size and actual levy percentages as additional predictors with SES resulted in a miniscule increment to the coefficient of determination $\left(R^{2}\right)$, raising it to $49.5 \%$. Table 6 presents the results for $4^{\text {th }}$ grade mathematics.

Mathematics $7^{\text {th }}$ Grade. The proportion of variance indicated $53 \%$ of the variance in $7^{\text {th }}$ grade mathematics was predictable from SES. The entrance of district size and actual levy percentages as additional predictors with SES resulted in a very marginal increment to the coefficient of determination in the regression model. Table 7 presents the results for $7^{\text {th }}$ grade mathematics. 
Table 6

Most Influential Predictor of 2003 WASL $4^{\text {th }}$ Grade Mathematics: Socioeconomic status (SES), District size, and Actual levy percentages

$4^{\text {th }}$ Grade Mathematics

\begin{tabular}{lccccccc}
\hline Predictor & $B$ & Beta & $r$ & $R$ & $R^{2}$ & $\begin{array}{c}R^{2} \\
\text { Increment }\end{array}$ & $\begin{array}{c}\text { Adjusted } \\
R \text { Square }\end{array}$ \\
\hline SES & -46.191 & -.723 & $-.689^{* *}$ & .689 & .475 & & .469 \\
District Size & -.004 & -.140 & -.047 & .703 & .495 & .020 & .482 \\
Actual Levy Percents & -5.920 & -.027 & $.355^{* *}$ & .704 & .495 & .000 & .476 \\
\hline
\end{tabular}

$F(3,78)=25.49 . \quad * * p<.01$

Table 7

Most Influential Predictor of 2003 WASL $7^{\text {th }}$ Grade Mathematics: Socioeconomic status (SES), District size, and Actual levy percentages

$7^{\text {th }}$ Grade Mathematics

\begin{tabular}{|c|c|c|c|c|c|c|c|}
\hline Predictor & B & Beta & $r$ & $R$ & $R^{2}$ & $\begin{array}{l}R^{2} \\
\text { Increment }\end{array}$ & $\begin{array}{l}\text { Adjusted } \\
R \text { Square }\end{array}$ \\
\hline SES & -71.054 & -.733 & $-.725^{* *}$ & .725 & .526 & & .520 \\
\hline District Size & .002 & .040 & .136 & .727 & .528 & .002 & .516 \\
\hline Actual Levy Percents & -8.012 & -.024 & $.378 * *$ & .727 & .528 & .000 & .510 \\
\hline
\end{tabular}

$F(3,78)=29.12 .{ }^{* *} p<.01$

\section{Research Summary}

This investigation explored relationships between district size, socioeconomic status, actual levy percentages, and their predictive influence on the Reading and Mathematics results of the criterion-referenced 2003 Washington Assessment of Student Learning (WASL) administered to $4^{\text {th }}$ and $7^{\text {th }}$ grade students who resided in $2^{\text {nd }}$ class Washington school districts. In this study, no statistical significant correlations between student achievement and district size were indicated. In a subsequent analysis, there were also non-significant results between student outcomes and district size at the 500-999, 1,000-1,499, and 1,5002,000 enrollment tiers.

When the relationship between student achievement and socioeconomic status was investigated, four statistical significant correlations in the negative direction were found with the entire sample districts. In a further analysis, three significant negative correlations were found between student performance and socioeconomic status at the 4\%-30\% 
levels, and at the 31\%-59\% SES level a single statistically significant negative correlation was evident. The 60-91\% socioeconomic status level produced a single statistically significant negative correlation. It is evident that socioeconomic status exerts a significant influence on student outcomes.

This study also examined the relationship between student outcomes and actual levy percentages, a component of fiscal resource allocation for Washington state school districts. Four statistically significant positive correlations were derived for the combined sample districts. In contrast, no statistically significant correlations were evident at the $0-15 \%$ actual levy percentage levels and student outcomes. Further, no statistically significant correlations were found at the $16-20 \%$ actual levy percentage levels and student achievement. Yet, interestingly at the 21-28\% actual levy percentage levels, two statistically significant positive correlations were evident with two subtests, $7^{\text {th }}$ grade reading and mathematics. These varied results for the tiered actual levy percentage comparisons were probably due to the smaller sample sizes for the subgroups.

\section{Conclusion}

In the final quantitative analysis, multiple linear regression procedures produced strong evidence that the socioeconomic status of the district was the predominant predictor of student performance on the 2003 WASL Reading and Mathematics subtests for $4^{\text {th }}$ and $7^{\text {th }}$ graders in Washington State $2^{\text {nd }}$ class school districts. These results extended and reinforced a significant amount of current literature (Abbott, Joireman, \& Stroh, 2002; Eigenbrood, 2004; Hopkins, 2005; Howley and Howley, 2004; Sirin, 2005; Spears, 2007; Weber, 2005) regarding the relationships between district size, socioeconomic status, district fiscal resources, and student achievement particularly in smaller and rural districts.

Although Hopkins (2005) findings substantiated similar investigations which confirmed the close relationship between SES and achievement, further observation of the data suggested that in terms of mathematics achievement, if a student is at the poverty level, mathematic achievement is at a higher level in a rural school setting. Hopkins proposed that smaller school system in rural settings allows some disadvantaged students to thrive academically in a community that is close-knit even though economically disadvantaged.

In perspective, smaller and rural school districts across Washington and in our nation continue to grapple with state and federal legislative mandates including the No Child Left Behind Act (2001) that place student outcomes at the highest priority in an aggressive political environment of high stakes assessment and achievement. As smaller and rural school districts struggle with increasing student achievement in the face of seemingly insurmountable hurdles such as poverty, a paucity of fiscal resources, enrollment shifts, dynamic demographic variances among students, constituent expectations, low levels of adult education, and generally lower property tax bases, further research is drastically needed in order to determine how these critical challenges can be mitigated in order to confront the nationwide underperformance within rural education.

As a postscript, the positive correlations that emerged between actual levy percentages and student achievement provide some glimmer of hope that through equitable, adequate, and appropriate public school fiscal practices, Washington school districts that are small and rural can overcome a portion of the strong and negative association between poverty and student outcomes. Certainly, this is promising news for the smaller and rural school districts in Washington as well as other districts nationwide that have similar achievement challenges for their students.

\section{References}

A Nation at Risk. (1983). Access: http://www.goalline.org/Goal\%20Line/NatAtRisk.html

Abbott, M., \& Joireman, J. (2001, July). The relationships among achievement, low income, and ethnicity across six groups of Washington State students. Access: http://www.spu.edu/wsrc

Abbott, M., Joireman, J., \& Stroh, H. (2002). The influence of district size, school size and socioeconomic status on student achievement in Washington: A replication study using Hierarchical Linear Modeling (Tech. Rep. No. 3). Seattle, WA: Seattle Pacific University, Washington State Research Center. Access: http://www.spu.edu/wsrc.

Bickel, R., \& Howley, C. (2000, May 10). The Influence of Scale on School Performance: A multi-level extension of the Matthew Principle. Education Policy Analysis Archives, 8 (22), ISSN 1068-234.

Boyle, M. (2002). Achieving small school success in Washington State. Washington Association of School Administrators. Access: http://www.wasaoly.org/resources/wasssuccess.pdf

Conant, J.B. (1959). The American high school today: A first report to interested citizens. New York, McGrawHill Book Company Inc.

Eigenbrood, R. (2004). The Relationship between socioeconomic status and the multilevel influence of school and district size on student achievement: A replication of two previous studies. Seattle, WA: Seattle Pacific University, Washington School Research Center. Access: http://www.spu.edu/wsrc

Fetler, M. (1989) School dropout rates, academic performance, size, and poverty: Correlates of educational reform. Educational Evaluation and Policy Analysis, 11(2), 109-116.

Fouts, J. (1999, January). School restructuring and student achievement in Washington State: Research findings on 
the effects of House Bill 1209 and school restructuring on Western Washington schools. Access:

http://www.spu.edu/orgs/research/currentresearch.html

Fouts, J. (2002, April). The power of early success: A longitudinal study of student performance on the Washington Assessment of Student Learning, 19982001. Access:

http://www.spu.edu/orgs/research/currentresearch.html

Fouts, J. (2003, April). A decade of reform: A summary of research findings on classroom, school, and district effectiveness in Washington State. Access: http://www.spu.edu/orgs/research/currentresearch.html Fouts, J., Abbott, M., \& Baker, D. (2002, May). Bridging the opportunity gap: How Washington elementary schools are meeting achievement standards. Access: http://www.spu.edu/orgs/research/currentresearch.html

Fouts, J., Brown, C., \& Thieman, G. (2002). Classroom instruction in Gates Grantree schools: A baseline report. Prepared for the Bill and Melinda Gates Foundation, Fouts and Associates, L.L.C.

Fouts, J., Stuen.C., Anderson, M., \& Parnell, T. (2000, May). The reality of reform: factors limiting the reform of Washington's elementary schools. Access: http://www.spu.edu/orgs/research/currentresearch.html

Friedkin, N., \& Necochea, J. (1988). School system size and performance: A contingency perspective. Education Evaluation and Policy Analysis, 10(3), 237-249.

Hopkins, T. (2005, Fall). If you are poor, it is better to be rural: A study of mathematics achievement in Tennessee. The Rural Educator, 27(1), 21-28.

Howley, C. (1989). Synthesis of the effects of school and district size: What the research says about achievement in small schools and school districts. Journal of Rural and Small Schools, 4(1), 2-12.

Howley, C. (1996, Spring). Compounding disadvantage: The effects of school and district size on student achievement in West Virginia. Journal of Research in Rural Education, 12(1), 25-32.

Howley, C. (2003). School reform proposals: The research evidence, small schools. Access: http://www.asu.edu.edu/educ/eps1/EPRU/documents/E PRO\%202002-101/Chapter\%2003-Howley-Final.pdf.

Howley, C., \& Howley, A., (2004, December). Smaller schools support student achievement. North Central Regional Center for Rural Development Policy Briefs. Access: http://www.ncrcrd.iastate.edu

Howley, C., Strange, M., \& Bickel, R. (2000). Research about school size and school performance in impoverished communities. (ERIC Document Reproduction Service No. EDO-RC-00-10)

Huang, G., and Howley, C., (1993, Winter). Mitigating disadvantage: Effects of small-scale schooling on student achievement in Alaska. Journal of Research in Rural Education, 9(3), 137-149.

Lake, R., Hill, P., O’Toole, L., \& Celio, M. (1999). Making standards work: Active voices, focused learning. Center on Reinventing Public Education: Daniel J. Evans School of Public Affairs, University of Washington, Seattle.

Lewis, A. (2008). Doing more with less. Phi Delta Kappan, 89(8), 547.

Lake, R., McCarthy, M., Taggart, S., \& Celio, B. (2000). Making standards stick: A follow-up look at Washington State's school improvement efforts in 19992000. Center on Reinventing Public Education: Daniel J. Evans School of Public Affairs, University of Washington. Seattle.

Mason, J. (2007). A case study of three rural schools: Factors, characteristics, and conditions that influence school performance scores. Published doctoral dissertation, Louisiana Tech University, Louisiana.

McCarthy, M. (2001). Washington elementary schools on the slow track under Standards-Based Reform. Center on Reinventing Public Education: Daniel J. Evans School of Public Affairs, University of Washington, Seattle.

Mork, C.R. (1998). Site-based management and teacher perceptions of restructuring outcomes in Washington State. Published doctoral dissertation, Seattle Pacific University, Seattle.

Newbill, G.C. (1999). Relationships between the degree of restructuring in Western Washington elementary schools and the results on Criterion Referenced $4^{\text {th }}$ grade assessments for Reading, Mathematics, Writing, and Listening. Published doctoral dissertation, Seattle Pacific University, Seattle.

No Child Left Behind Act. (2001) Public Law 107-110, 107th Congress.

Peterson, K., \& Abbott, M., (2005). The power of early success 1998-2004: A follow-up study on the determinants of student performance (Tech. Rep. No. 8). Access: http://www.spu.edu/wsrc

Portin, B., Plecki, M., Elfers, A., \& Beck, L. (2003). Leadership for school renewal: influence of resource opportunities. A paper presented at the Annual Meeting of the American Educational Research Association, April 21-25, Chicago, Ill.

Revised Code of Washington 28A.300.065. Classification and numbering system of school districts.

Sirin, S. (2005). Socioeconomic Status and Academic Achievement: A meta-analytic review of research. Review of Educational Research, 75(3), 417-453.

Spears, R. (2007). Funding equity and student achievement: An analysis and comparison of Kentucky and Tennessee: Published doctoral dissertation, Tennessee State University, Tennessee.

Van Slyke, G. (1998). Effects of school reform legislation: The relationship of student achievement gains and degree of restructuring on selected Western Washington schools. Published doctoral dissertation, Seattle Pacific University, Seattle. 
Walberg, H., \& Walberg, H. (1994). Losing Local Control. Educational Researcher, 23(5), 19-26.

Washington Kids Count. (2001). Exploring disparities in education achievement: The impact of school funding (Tech. Rep.). Seattle, WA: University of Washington, Washington Kids Count, Human Services Policy Center, Daniel J. Evans School of Public Affairs.
Weber, C. (2005). School size, student achievement, and the equity of achievement in California. Published doctoral dissertation, University of California, Irving. 